\title{
A ETNOBOTÂNICA NA FACULDADE DE CIÊNCIAS AGRONÔMICAS, UNESP - BOTUCATU - SP
}

\author{
ETHNOBOTANY AT THE FACULTY OF AGRONOMIC SCIENCES, UNESP - \\ BOTUCATU - SP
}

Lin Chau MING*; Izabel de CARVALHO

Faculdade de Ciências Agronômicas - UNESP, Fazenda Experimental Lageado, CEP 18.603-970, Botucatu - São Paulo. bel@fca.unesp.br; *lin.ming@.unesp.br

\begin{abstract}
RESUMO
Neste artigo é apresentada uma descrição do ensino da disciplina Etnobotânica, em nível de graduação e pós-graduação, na Faculdade de Ciências Agronômicas (FCA), UNESP - Botucatu - SP, com os antecedentes de sua formulação, seu desenrolar e os resultados obtidos desde seu início até o presente. Diferentes atividades foram desenvolvidas durante esse período, sendo também destacados os projetos de pesquisa e extensão, bem como os trabalhos acadêmicos e científicos produzidos. São apresentados os desafios gerais na área e na FCA.
\end{abstract}

Palavras-chave: etnobotânica; ensino; pesquisa; educação

\begin{abstract}
This article presents a description of the teaching of the discipline Ethnobotany, at undergraduate and graduate levels, at the Faculty of Agronomic Sciences (FCA), UNESP - Botucatu - SP, with the background of its formulation, its development and the results obtained since its beginning to the present. Different activities were developed during this period, with emphasis on research and extension projects, as well as the academic and scientific works produced. The general challenges in the area and in the FCA are presented.
\end{abstract}

Keywords: ethnobotany; teaching; research; education

\section{INTRODUÇÃO}

As áreas de Etnobiologia e Etnoecologia têm apresentado crescimento significativo no Brasil e são ciências que, sob conceitos e olhares diversos, procuram viabilizar a sistematização, em caráter científico, dos conhecimentos tradicionais acerca das diversas nuances da natureza de uma dada região. Sua importância é representada pela produção de subsídios para propostas de desenvolvimento sustentável das regiões, envolvendo a manutenção de nossa rica diversidade biológica e cultural.

Desde a Declaração de Belém, em 1988, que os pesquisadores que trabalham nessa área iniciaram as primeiras articulações para que esta pudesse adquirir e ter reconhecido seu status de Ciência e divulgar para a comunidade científica sua primeira versão do código de ética. E até os dias de hoje, quando diversos grupos de pesquisadores se envolvem em trabalhos nos mais diversos recantos brasileiros, com diferentes comunidades indígenas e tradicionais, as Etnociências têm se voltado para fazer a ponte entre as ciências tradicionais e as ciências convencionais.

No Brasil, a área tem apresentado crescimento em suas subáreas/interfaces como Etnobotânica, Etnozoologia, Botânica Econômica, Etnoagricultura, Antropologia, Ecologia Humana e outras. Diversos pesquisadores têm realizado trabalhos desde décadas passadas e a consolidação disso também é verificada na forma de disciplinas oferecidas em currículos regulares de alguns cursos universitários, em nível de graduação e pós-graduação, de acordo com levantamento realizado por Alves (2001). Vale citar que disciplinas de graduação e pós-graduação têm sido oferecidas há mais de 20 anos, e nos últimos anos tem havido uma expansão, com a implantação de disciplinas em outros cursos de graduação, mestrado e doutorado.

Junto com essa situação de crescimento, a área vem mostrando melhor nível de organização, intercâmbio e divulgação dos diversos trabalhos existentes. Desde 1996, quando foi fundada a Sociedade Brasileira de Etnobiologia e Etnoecologia, em resposta à implantação de um trabalho sistemático que já vinha acontecendo na Bahia nessa área (SERRA, 2001), em Feira de Santana, é 
realizado um simpósio nacional a cada dois anos e encontros regionais nos interstícios. Isso tem representado uma importante contribuição para que os trabalhos da área sejam divulgados e reconhecidos.

Incentivar a formação e oferecimento de disciplinas relacionadas à área nos currículos de cursos de Biologia, Agronomia, Ecologia, Ecologia, Antropologia e cursos afins, tanto em nível de graduação quanto na pós-graduação, é uma das maneiras. Algumas escolas já o fizeram. Estruturaram disciplinas, mantêm equipes de alunos trabalhando em diferentes projetos de pesquisa, oferecem cursos de extensão universitária, conseguem recursos para viabilizar os projetos em campo e sempre têm convidado pesquisadores estrangeiros para ministrar cursos ou proferir palestras (ALVES, 2001; COSTA NETO, 2001; AMOROZO et al., 2002).

Intercâmbios são também fundamentais, pois permitem o contato com informações e profissionais que têm outras experiências, colocando as pessoas em contato com outras visões da situação. Algumas experiências têm sido realizadas no país.

As áreas de Etnobiologia e Etnoecologia ainda carecem de corpo docente disponível para atender às crescentes necessidades de trabalho em instituições e universidades que agora começam a abranger essas áreas de pesquisa. Há necessidade premente de formação de recursos humanos para satisfazer tal demanda. No Brasil, a grande maioria dos docentes e mesmo pesquisadores dessas áreas é egressa de programas de Ciências Biológicas, provendo as necessidades teóricas de cunho social e cultural por estudos específicos e mesmo autodidatismo. Nos Estados Unidos, as Etnociências são tradicionalmente ocupadas por profissionais ligados às áreas antropológicas/sociais (AMOROZO et al., 2002).

O Brasil ocupa um lugar importantíssimo em termos mundiais quando o assunto é biodiversidade, pois é o país com maior diversidade de grandes grupos de seres vivos, como, por exemplo, as plantas. Os diferentes biomas existentes mostram um quadro multifacetado dessa diversidade.

Associado a isso, o Brasil também é rico em diversidade cultural. Apresenta cerca de 200 etnias indígenas (ISA, 2016) e um sem número de outros povos, provenientes de diversas regiões do mundo, os quais, nesses mais de quinhentos anos de ocupação espacial e cultural, em contato com o ambiente local, estão definindo mais e mais as características de sua população, suas tradições culturais e seus conhecimentos associados.

\section{A Etnobotânica no Brasil}

No Brasil, dentre as subáreas das Etnociências, uma se sobressai. Trata-se da Etnobotânica, subárea provavelmente mais antiga e a que mantém em seu âmbito um conjunto de professores e pesquisadores com um repertório de publicações e experiências mais consolidado e que, na ativa, continua a atrair novos pesquisadores e estudantes interessados nessa área.

Fruto desse processo mais antigo e consistente de realização de trabalhos, a Etnobotânica vem obtendo, a cada ano, um espaço maior entre as sociedades científicas. A Sociedade Botânica do Brasil mantém em sua estrutura organizacional o Grupo de Trabalho em Etnobotânica, encarregado de organizar e fomentar a área dentre os associados. Esse grupo se reúne no mínimo anualmente e durante os Congressos Nacionais discute temas relacionados com as necessidades da área, em reuniões satélites, além de promover, em conjunto com as comissões organizadoras, eventos técnicos, como palestras, mesas redondas e mini-cursos.

Agregado ao GT, há uma rica parceria com o GELA, Grupo Etnobotânico Latino-Americano, ampliando as ações em outros países irmãos. Diversas atividades conjuntas têm sido realizadas entre as entidades, com benefícios comuns.

A Sociedade Botânica do Brasil também estabeleceu um comitê assessor dentro de sua revista científica, Acta Botânica Brasílica, na área de Etnobotânica, permitindo que os trabalhos realizados nesse setor possam ser publicados e divulgados com maior intensidade e abrangência, com qualidade adequada, visto serem avaliados por pessoas experientes.

A partir de 1996, com a fundação da Sociedade Brasileira de Etnobiologia e Etnoecologia (SBEE), a Etnobotânica passa a ter outro canal de comunicação com a sociedade. Boa parte dos sócios fundadores da SBEE é dessa área e a maioria dos trabalhos apresentados em seus seminários nacionais ou regionais bienais também.

No Brasil, a Etnobotânica tem conseguido um espaço crescente nos meios acadêmicos. Na área de ensino em nível de graduação e pós-graduação, alguns dados foram obtidos por Fonseca-Kruel, Silva 
e Pinheiro (2005), num levantamento acerca do ensino acadêmico de Etnobotânica no Brasil. São hoje oito Universidades que oferecem essa disciplina nos currículos de graduação e nove na pós-graduação, nas áreas de Agronomia, Biologia, Farmácia e Engenharia Florestal. Estas Universidades abrangem todas as regiões geográficas brasileiras. Em áreas afins (Etnobiologia, Ecologia e Manejo de Ecossistemas, Botânica Econômica, Farmacognosia, Etnoecologia, Plantas Medicinais, Ecologia Humana, Plantas Hortícolas e Medicinais, Botânica Aplicada e Etnofarmacologia e outras), a Etnobotânica está incluída em tópicos destas disciplinas, em 24 cursos de graduação e nove programas de pós-graduação, em Universidades de todas as regiões brasileiras, nas mesmas áreas de pesquisas citadas anteriormente.

Há uma concentração dos cursos e disciplinas na região Sudeste e Nordeste (51 e 31\%, respectivamente), provavelmente devido à existência de maior número de Universidades e docentes interessados nessas regiões. As regiões Norte e Centro-Oeste, com biomas considerados de alta diversidade vegetal e cultural, apresentam menor número de instituições de ensino que abordam o tema, o que revela a necessidade da implementação de cursos e programas para o desenvolvimento desta disciplina nestes locais.

Na Unesp, há disciplinas de Etnobotânica nos programas de graduação e pós-graduação nos campi de Rio Claro e Botucatu, tendo sido elaboradas e oferecidas a partir de 1996. A análise dos conteúdos programáticos das disciplinas nas instituições de ensino revelou aspectos comuns com relação à abordagem conceitual da Etnobotânica, inserindo temas atuais, como a prospecção da biodiversidade, o desenvolvimento de novos produtos, a conservação da natureza e o uso sustentável dos recursos vegetais. Temas específicos são também focados devido à diversidade cultural própria às diversas regiões brasileiras (MARQUES, 2002).

Há, contudo, uma carência de materiais bibliográficos, com a utilização de poucas fontes e em geral manuais estrangeiros. Essa realidade começa a ser mudada aos poucos, a partir de algumas publicações relacionadas às técnicas e métodos de pesquisa em Etnobotânica no Brasil, com caráter didático.

Esse retrato mostra um grande crescimento da área nos currículos acadêmicos brasileiros, havendo ainda outras disciplinas em processo de regulamentação, o que coloca a área como uma das que apresentam grandes índices de expansão.

Em 2005, fruto também do reconhecimento da Etnobotânica como uma subárea científica mais consolidada, o CNPq, ouvindo a comunidade científica brasileira, apresenta uma proposta de discussão das novas áreas e subáreas de pesquisa no Brasil. Nesta proposta, a Etnobotânica está colocada como subárea da Botânica, situando-se no mesmo nível hierárquico que outras, como a Morfologia, Sistemática, Fisiologia etc. Isso representa um grande avanço para a área, incentivando ainda mais a ação dos pesquisadores envolvidos e atraindo novos interessados. Processo semelhante ocorreu com a subárea de Etnofarmacologia, nos anos 1980, quando ela foi inserida na área de Farmacologia, após processo de reestruturação das áreas científicas do CNPq (MING, 2018).

\section{O ensino de Etnobotânica na FCA- UNESP/Botucatu - SP.}

O ensino de Etnobotânica na Faculdade de Ciências Agronômicas, UNESP - Botucatu, SP, veio atender a uma demanda que estava sendo sentida há alguns anos. Com os seus anos de funcionamento, vem satisfazendo uma necessidade de capacitação e habilitação do profissional da área agronômica que, além de disciplinas das áreas tecnológicas próprias, requer experiências no trato com os agricultores, de acordo com suas características sociais e culturais locais.

No ensino de graduação isso está estampado na grande porcentagem de alunos inscritos por turma (cerca de $80 \%$ do número de alunos ingressantes em cada ano), a partir de sua implementação, em 1999, para o curso de Agronomia. Foram, em todos esses anos, 64 alunos matriculados (duas turmas de 32 alunos) na disciplina. No ano de 2001, foi aberta outra disciplina optativa, para o curso de Engenharia Florestal, com a inscrição de porcentagem semelhante ao da Agronomia.

Essas disciplinas foram efetivadas após a realização de cursos preliminares, oferecidos em 1997, com a disciplina inserida dentro do curso de Especialização em Botânica oferecido pelo Departamento de Ciências da Natureza da Universidade Federal do Acre, em Rio Branco (Figura 1), e a seguir no programa de Pós-Graduação em Agronomia, área de concentração Horticultura, da UNESP - Botucatu, em 1998, oferecida bienalmente e posteriormente nos programas de graduação em Agronomia e Engenharia Florestal. 
Essa disciplina de pós-graduação foi ministrada com a participação da Profa. Maria Christina de Mello Amorozo, do Departamento de Ecologia, Instituto de Biociências da UNESP - Rio Claro, desde o início do oferecimento da disciplina até a aposentadoria da professora Amorozo, ocorrida em 2015.

Dentro de uma estratégia para o desenvolvimento mais gabaritado da área na FCA, a vinda de outros professores da área para ministrar disciplinas foi efetivada em vários anos. Podem ser citadas as vindas dos seguintes professores:

1998 - Prof. Javier Caballero, da Universidade Nacional Autónoma do México, quando ministrou disciplina de "Métodos quantitativos em Etnobotânica" (Figura 2);

1999 - Prof. Miguel Alexiades, do Jardim Botânico de Nova York, ministrando a disciplina “Acercamientos en Etnobotánica" (Figura 3);

2000 - Prof. William Balée, da Universidade de Tulane, Geórgia, EUA, com a disciplina "Etnobotânica"; 2005 - Prof. Miguel Piñedo Vásquez, da Universidade de Columbia, New York, EUA, ministrando a disciplina "Agrobiodivesidade";

2006 - Prof. Nivaldo Peroni - UNICAMP, com a disciplina "Análise quantitativa em Etnobotânica";

2010 - Profa. Andrea Martinez-Balleste, da Universidad Nacional Autónoma de México, com a disciplina "Aspectos quantitativos em Etnobotânica";

2013 - Profa. Fátima Cruz Souza, da Universidad de Valladoilid, Palência, Espanha, com a disciplina "Desenvolvimento rural e sustentabilidade social";

2014 - prof. Javier Caballero, da Universidade Nacional Autónoma do México, com a disciplina "Métodos quantitativos em Etnobotânica".

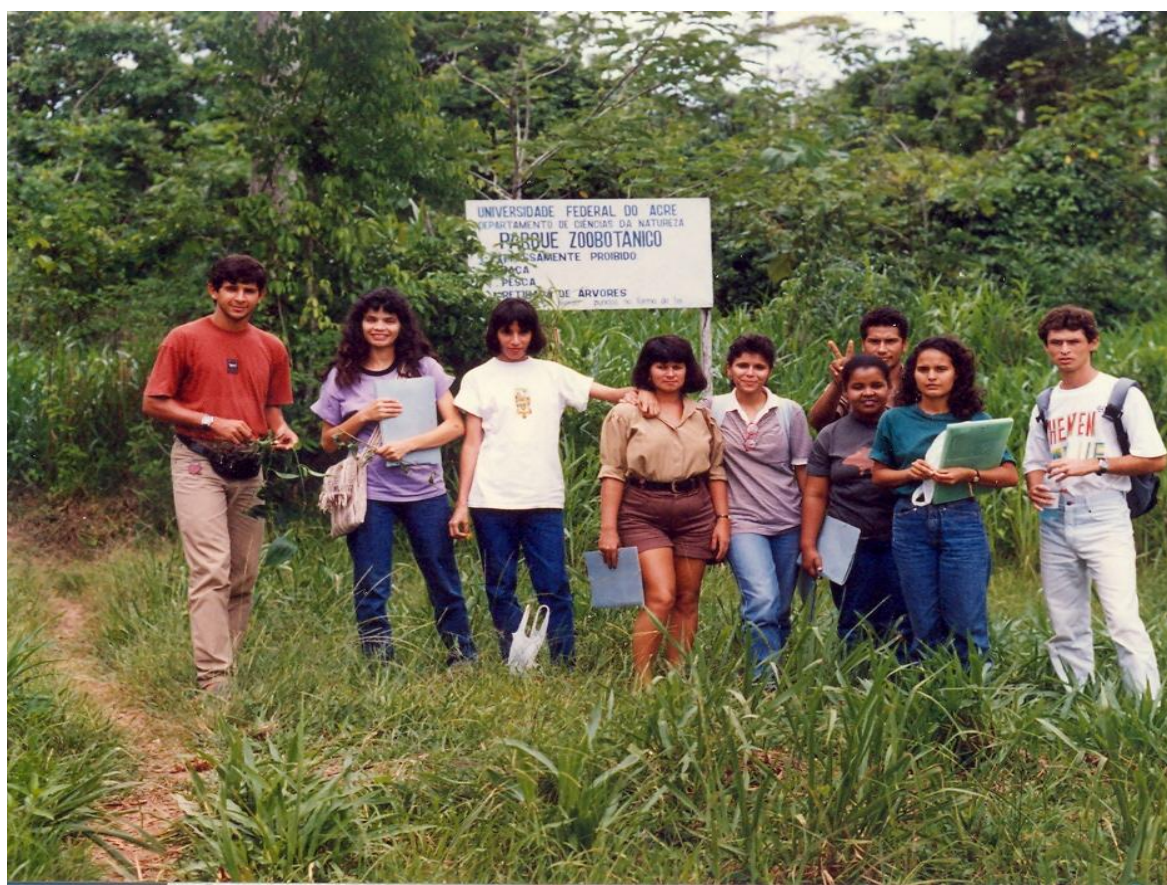

Figura 1. Curso ministrado na Universidade Federal do Acre. 


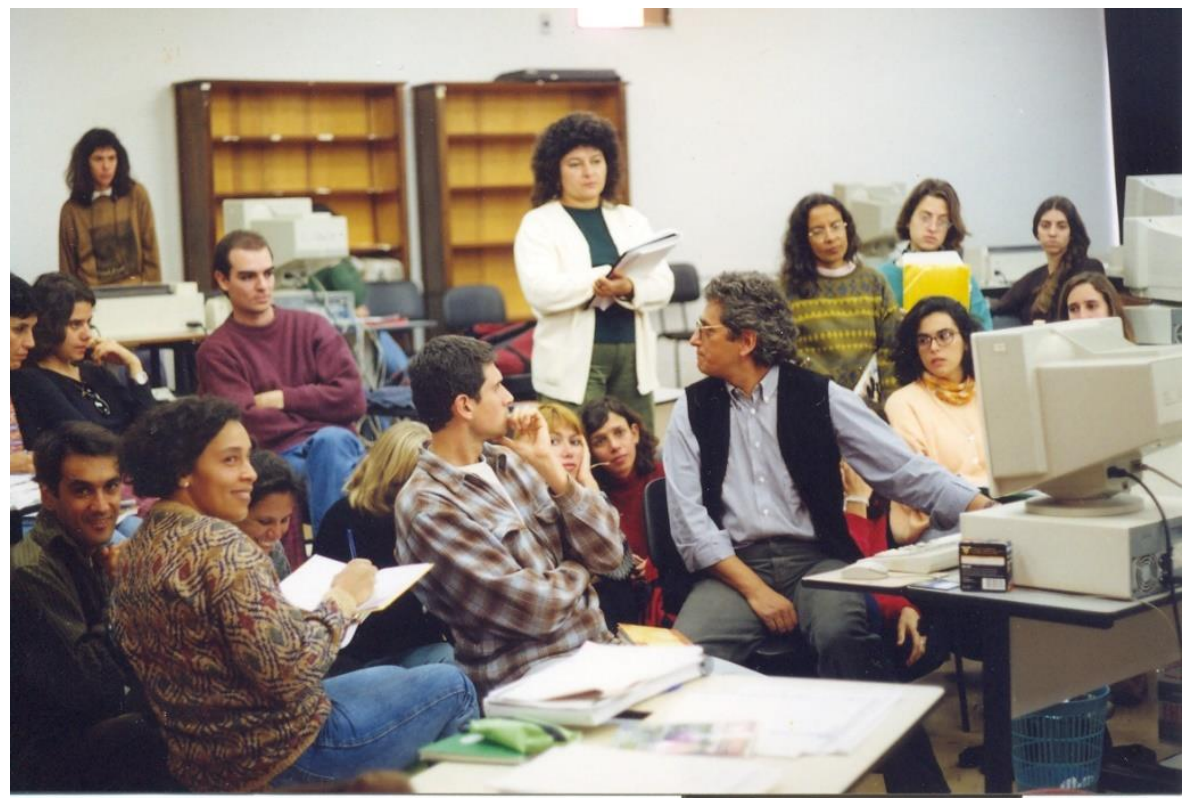

Figura 2. Disciplina ministrada por Javier Caballero na FCA em 1999.

Essas disciplinas permitiram aos participantes, além do aprofundamento de várias questões teóricas e metodológicas na área de Etnobotânica, ter contato com diferentes visões e pensamentos de outros pesquisadores, ajudando no embasamento dos alunos. Junto com assuntos teóricos, em todas as disciplinas ministradas, atenção especial é dada para as atividades práticas, com a realização de práticas em campo, em contato direto com comunidades tradicionais ou indígenas, em períodos compreendidos entre 15 a 22 dias, quando exercícios práticos de aplicação de conteúdos específicos e vivência com comunidades são realizados, permitindo também uma maior imersão nos ambientes culturais e florestais de cada uma das localidades.

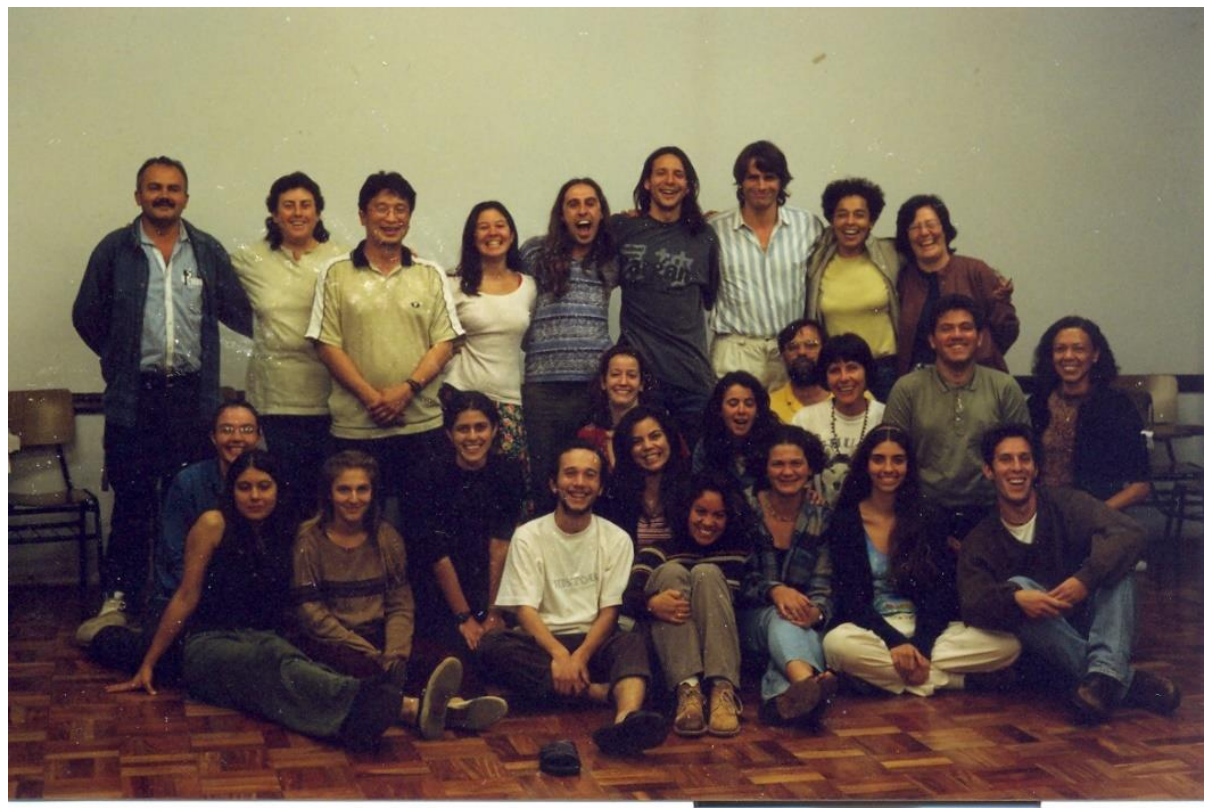

Figura 3. Disciplina ministrada por Miguel Alexiades na FCA em 2000.

Foram realizadas viagens para atividades práticas em comunidades tradicionais do Vale do Paraíba (1998) e Serra da Mantiqueira (2000), SP, vivência em comunidades quilombolas e de caboclos no Vale do Ribeira, SP (Figura 4) (2002 e 2004), comunidades Indígenas Xavante (2006) e Paresi (2008) - MT de seringueiros na Reserva Extrativista Chico Mendes - AC (Figuras 5 e 9) (2010, 2012 e 2014), comunidades indígenas Kaxinawá, AC, (2016), comunidades indígenas do Negro, região de Manaus, AM (2018) e em 2020 será realizada em comunidade indígena Suruí-Paiter, em Rondônia. 


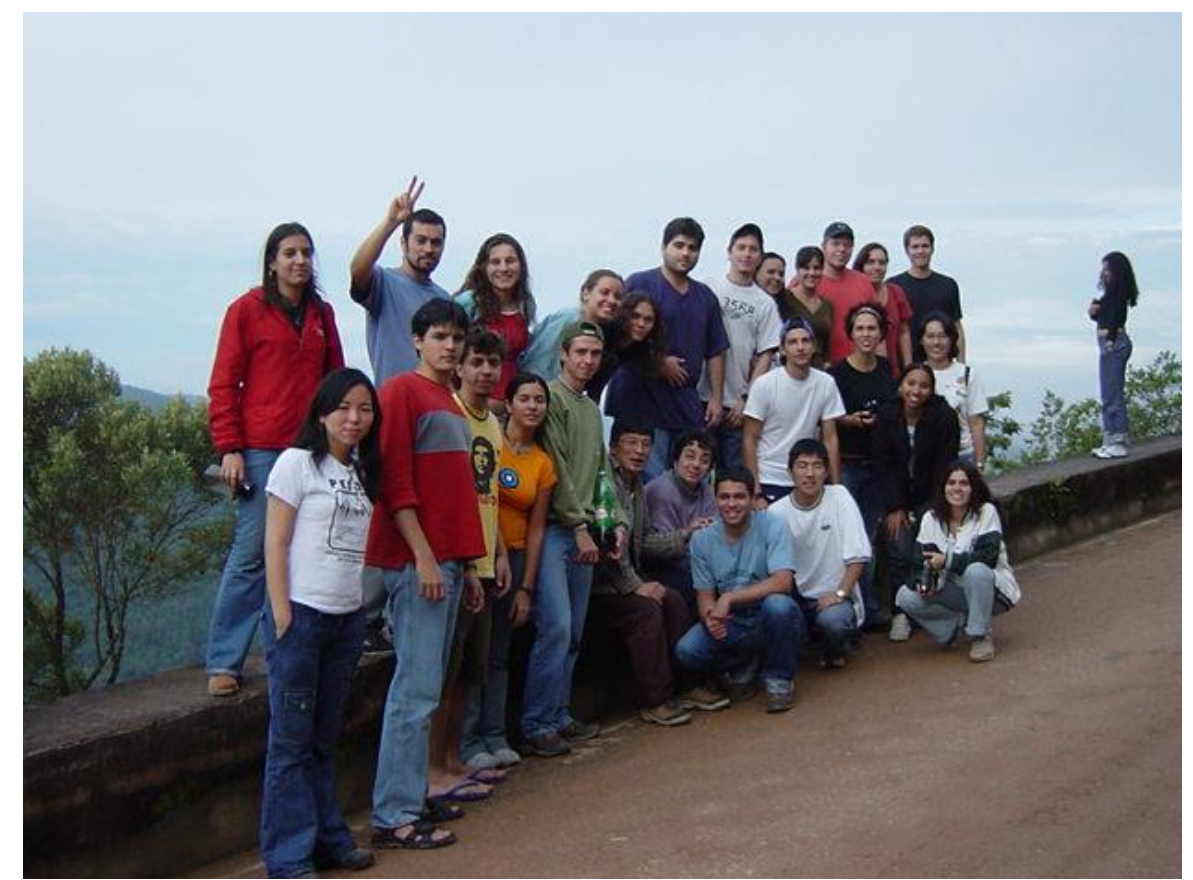

Figura 4. Estudantes de graduação em viagem de aula prática ao Vale do Ribeira, SP.

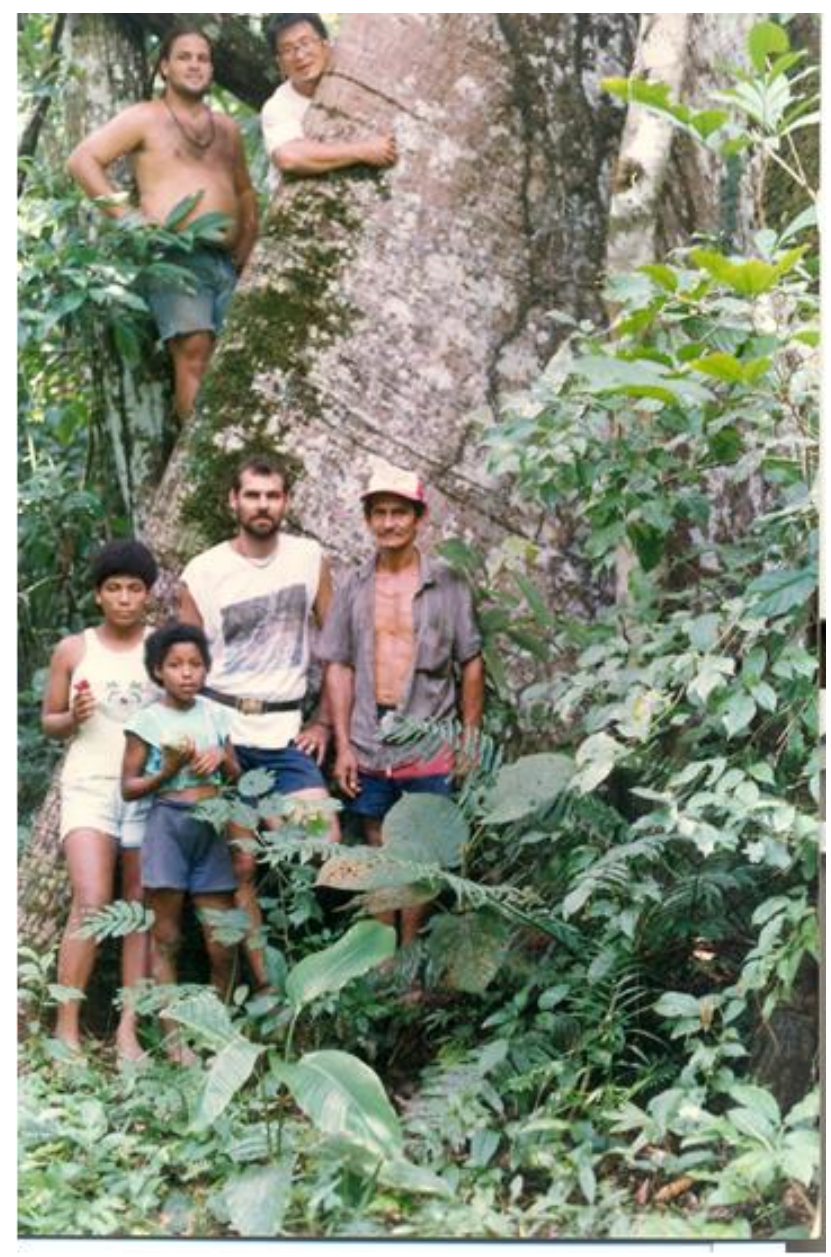

Figura 5. Estudantes de graduação na Reserva Extrativista Chico Mendes, Acre.

Vários projetos de pesquisas, aprovados por órgãos de fomento, foram realizados, envolvendo estudantes de graduação e pós-graduação. Isso permitiu a participação mais ativa em trabalhos de campo, uma experiência importante para o futuro profissional deles. Exemplos de alguns dos projetos aprovados e seus órgãos financiadores foram: 
2017 - Plantas alimentícias utilizadas por comunidades indígenas em São Gabriel da Cachoeira, Amazonas: análise de dados botânicos e etnobotânicos junto ao herbário e biblioteca do The New York Botanical Garden, New York, USA (CAPES);

2015 - Plantas alimentícias de uso local no Brasil, Moçambique e Etiópia, com ênfase na alimentação escolar $(\mathrm{CNPq})$;

2014 - Povos amazônicos, plantas alimentícias: estudos para a sustentabilidade e conservação regional (CAPES);

2014 - Cooperação Acadêmica nas áreas de Etnobotânica, Botânica Econômica e Sistemática (CAPES);

2011 - Projeto Temático: Rede de Pesquisa de compostos químicos vegetais para controle de malária a partir da etnofarmacologia nos Estados do Amazonas e Acre (CNPq);

2011 - Conservação e uso da agrobiodiversidade na segurança alimentar de etnias indígenas do Estado do Mato Grosso (CNPq);

2011 - Consolidação do Grupo Timbó de Pesquisa e Extensão em Agroecologia, da Faculdade de Ciências Agronômicas - UNESP- Botucatu- SP (CNPq);

2008 - Tecnologias agroecológicas para agricultura familiar em comunidades remanescentes de quilombos e seu entorno, no município de Iporanga, SP (CNPq) (Figura 6);

2008 - Plantas antimaláricas da calha do Rio negro, Amazonas (FAPESP);

2005 - Tecnologias agroecológicas para agricultura familiar em comunidades remanescentes de quilombos e seu entorno, nos municípios de Apiaí, Iporanga e Itaoca, SP (FAPESP) (Figura 7);

2005 - Polo de biotecnologia para o maneja sustentável da agrobiodiversidade da Mata Atlântica por comunidades do Vale do Ribeira (Ministério do Meio Ambiente);

2005 - Diagnóstico da alimentação na saúde do povo Xavante - Mato Grosso (CNPq) (Figura 8);

2004 - Plantas antimaláricas da calha do rio Solimões e região de Manaus (FAPESP);

2004 - Estudos etnobotânicos dos recursos vegetais nos terreiros de uma comunidade remanescente de quilombo do Vale do Ribeira, SP (FAPESP);

2004 - Hortaliças, frutas e plantas medicinais utilizadas por comunidades tradicionais no município de Iporanga, SP (FAPESP);

2004 - Bioprospecção de plantas medicinais com atividade anticâncer, pressão alta, colesterol e atividade diurética na APA da Serra da Mantiqueira, SP, (FAPESP);

2002 - Estudos etnobotânicos qualitativos e quantitativos em comunidades tradicionais no PETAR Parque Estadual e Turístico do Alto Ribeira e seu entorno, Iporanga, SP (FAPESP);

1999 - Plantas medicinais do Horto Florestal de Itatinga: uma visão do uso pelos moradores da comunidade (FAPESP);

1998 - Uso de plantas medicinais pela comunidade da Fazenda Lageado, Botucatu - SP (FAPESP);

1996 - Caracterização de ambientes, ocorrência e manejo de plantas medicinais na Reserva Extrativista Chico Mendes, AC (FAPESP).

Dos projetos realizados, alguns trabalhos receberam prêmios ou menções, como os apresentados a seguir:

2004 - Voto de Aplauso consignado nos Anais do Senado Federal, em 07/07/2004, pelos trabalhos realizados na pesquisa etnofarmacológica de plantas para tratamento da malária no Estado do Amazonas;

2011 - Prêmio de Melhor Publicação na área de Sustentabilidade Ambiental, pelo livro Polo de Biotecnologia da Mata Atlântica: relatos de pesquisas e outras experiências vividas no Vale do Ribeira, Instituto Negócios Públicos do Brasil - Sustentabilidade Ambiental - Curitiba - PR;

2011 - Prêmio “Cultura Indígena 4a Edição Raoni Metuktire”, pelo trabalho realizado com os Paresi, MT, promovido pela Secretaria de Cidadania e Diversidade Cultural do Ministério da Cultura;

2013 - Menção Honrosa de resumo apresentado no III Encontro Internacional de Agroecologia, em Botucatu, com trabalho na Reserva Extrativista Chico Mendes, AC;

2017 - Menção no Prêmio Juliana Santilli de Agrobiodiversidade em 2017, promovido pelo Instituto SocioAmbiental, com os trabalhos realizados com os povos Paresi no Estado do Mato Grosso;

2018 - Professor homenageado pela Sociedade Brasileira de Etnobiologia e Etnoecologia, durante o evento em Belém, PA, pelas importantes contribuições em prol da Etnobiologia e Etnoecologia no Brasil.

Além disso, projetos de Extensão Rural foram aprovados pelo CNPq, durante cinco anos consecutivos, na região do Vale do Ribeira, com comunidades quilombolas, nos municípios de Apiaí e Iporanga, SP e em assentamentos rurais em Iaras, SP e também pelo Ministério do Desenvolvimento Agrário, com comunidades indígenas Paresi e Xavante, ambas no Mato Grosso. 


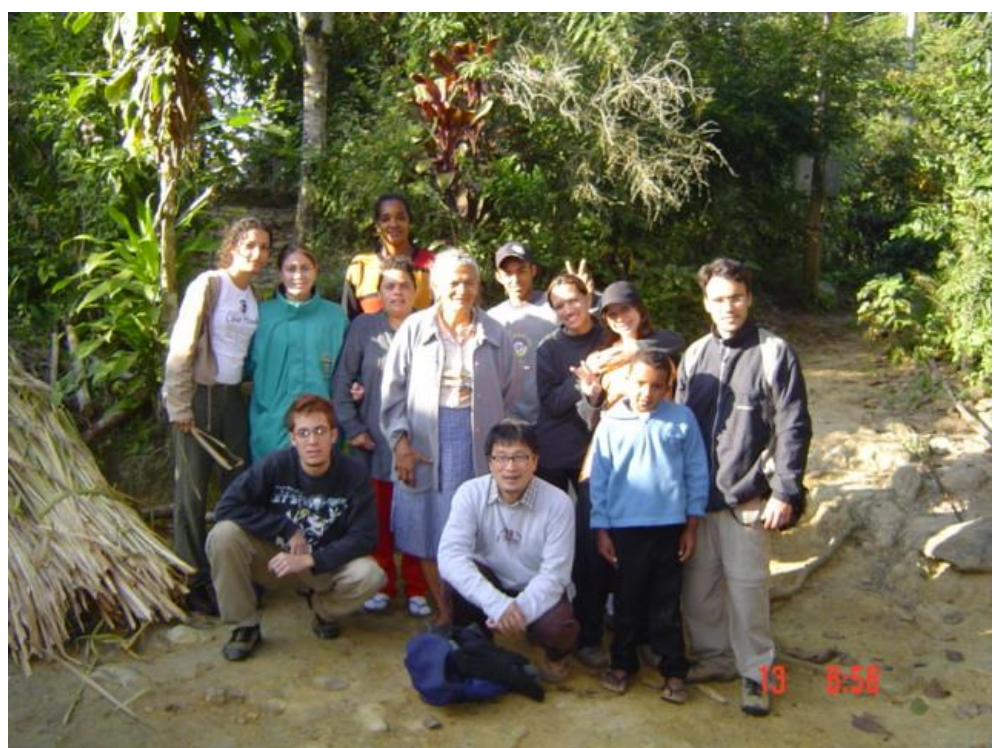

Figura 6. Trabalho em comunidade tradicional em Iporanga, SP.

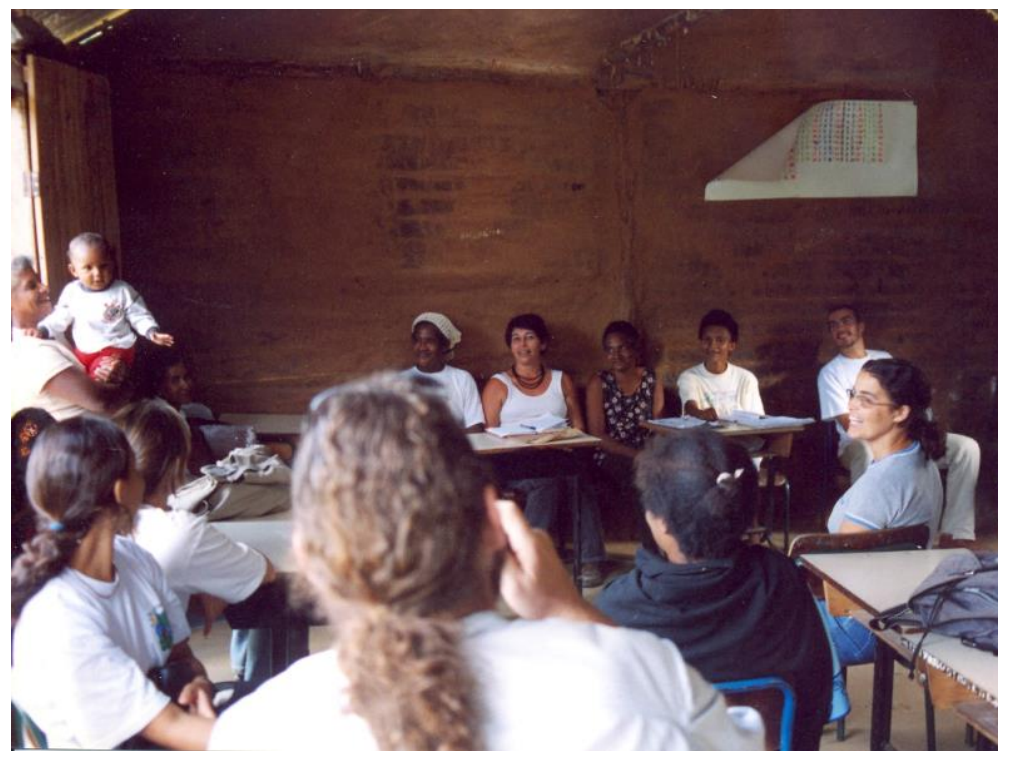

Figura 7. Reunião em comunidade quilombola em Iporanga, SP.

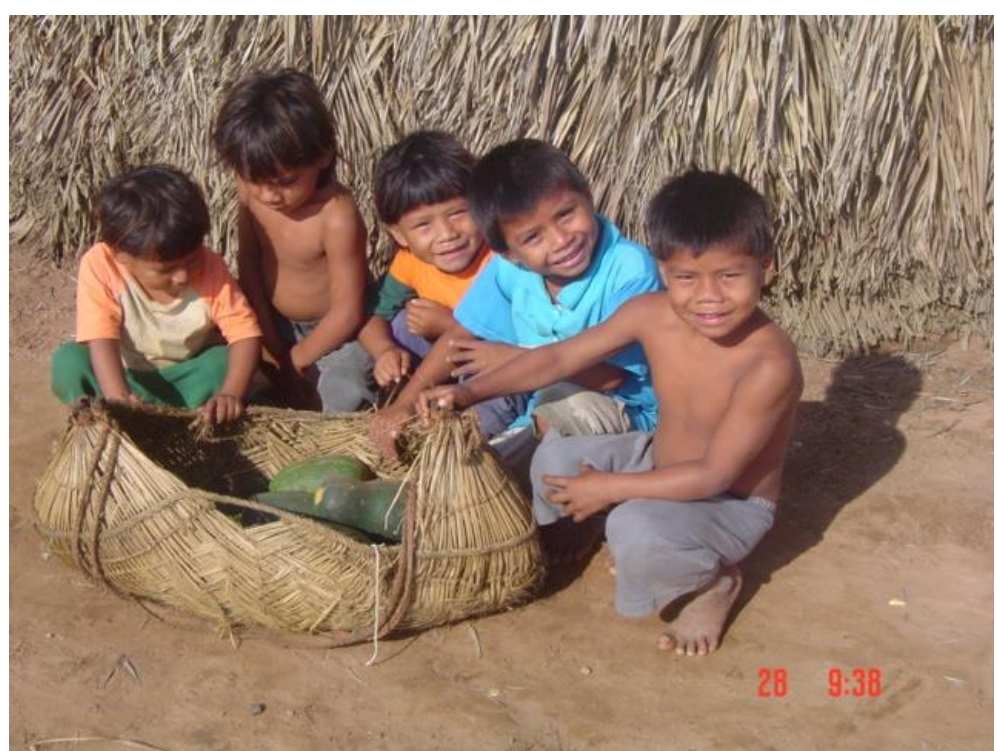

Figura 8. Crianças Xavante com cesto com abóboras. 
A FCA organizou e promoveu também encontros científicos da área, como, por exemplo: $2^{\circ}$ Seminário de Etnobiologia e Etnoecologia da região Sudeste, em 2003; $3^{\circ}$ Seminário de Etnobiologia e Etnoecologia da região Sudeste em 2005; $5^{\circ}$ Seminário de Etnobiologia e Etnoecologia da região Sudeste, em 2015. Nestes eventos, alunos de graduação e pós-graduação puderam participar como membros das comissões organizadoras e de apoio, podendo ter experiência nessas atividades, além de ter contato com outros pesquisadores, representantes de comunidades tradicionais e indígenas convidados e participantes nos eventos.

Como resultado de várias das atividades realizadas, foram também publicados livros referentes à temática etnobotânica, envolvendo professores e estudantes de graduação e pós-graduação, tanto da FCA como de outras faculdades. A lista desses livros está abaixo, em ordem cronológica decrescente:

1. SOUTO, F.J.B.; SOLDATI, G.T.; MING, L.C.; DUQUE-BRASIL; KUBO, R.R. Quando pensa que não... contos, crônicas e causos em Etnoecologia, v. 3. Feira de Santana: Sociedade Brasileira de Etnobiologia e Etnoecologia, 2018, 212p.

2. MING, L.C.; AMOROZO, M.C.M.; FERREIRA, A.B. Experiências Etnobotânicas na Reserva Extrativista Chico Mendes, Acre. Botucatu: Fundação de Estudos e Pesquisas Agrícolas e Florestais, 2018. $148 \mathrm{p}$.

3. MING, L.C.; DO VAL, M.F.; FRANCO, F.S.; CARMO, M.S.; SANTOS, M. Plantando sonhos: experiências agroecológicas no Estado de São Paulo. Feira de Santana: Sociedade Brasileira de Etnobiologia e Etnoecologia, 2018. 311p.

4. MING, L.C.; HIDALGO, A.F.; CHAVES, F.C.M.; HAVERROTH, M.; KINUPP, V.F. Plantas para malária e males associados no Rio Negro e Rio Purus: aspectos etnobotânicos e agronômicos. Botucatu: Fundação de Estudos e Pesquisa Agrícolas e Florestais, 2018. 222p.

5. TOMCHINSKY, B.; MING, L.C. Plantas alimentícias de uso local no Brasil, Moçambique e Etiópia com ênfase na alimentação escolar. Botucatu: Fundação de Estudos e Pesquisas Agrícolas e Florestais, 2018. 168 p.

6. SIVIERO, A.; MING, L.C.; SILVEIRA, M.; DALY, D.C.; WALLACE, R.H. Etnobotânica e Botânica Econômica do Acre. Rio Branco: Editora da Universidade Federal do Acre, 2017. 416p.

7. SOUTO, F.J.B.; DUQUE-BRASIL, R.; SOLDATI, G.T.; MING, L.C.; COSTA-NETO, E.M. Quando pensa que não... contos, causos e crônicas em etnoecologia, v. 2. Feira de Santana, Bahia: Editora Zarte, 2016, 295p.

8. MING, L.C. Seringas, seringueiras e seringueiros. Botucatu: Fundação de Estudos e Pesquisas Agrícolas e Florestais, 2015. 106p.

9. MING, L.C. As vendedoras de hortaliças de Shanghai. Botucatu: Fundação de Estudos e Pesquisas Agrícolas e Florestais, 2015. 140p.

10. SILVA, A.L.; CHAVES, F.C.M.; HIDALGO, A.F.; MING, L.C. Plantas antimaláricas em comunidades tradicionais de Boca do Acre, Amazonas. Botucatu: Fundação de Estudos e Pesquisas Agrícola e Florestais, 2015. 24p.

11. TRIVELLATO, C.; MING, L.C.; MAHSA, A.E.I.Y. Plantas para o tratamento da malária e males associados de parte do povo Ye'pa Mahsã - Uhuake ko Tohonika Ahpeye do'atise Re Ye'pa Mahsã na Ohkotise. Botucatu: Fundação de Estudos e Pesquisas Agrícolas e Florestais, 2015. 22p.

12. MING, L.C. Somos só professores? Botucatu: Fundação de Estudos e Pesquisas Agrícolas e Florestais, 2015. 180p.

13. TOMCHINSKY. B; MING, L.C. Estudo de plantas antimaláricas em Barcelos, Amazonas. Botucatu: Fundação de Estudos Agrícolas e Florestais, 2015. 28p.

14. HIDALGO, A.F.; VIANA JR, J.M.; BONFIM-NETTO, J.V.; MING, L.C. Saracura-mirá: a planta que sara e cura (Ampelozizyphus amazonicus Ducke). Botucatu: Fundação de Estudos e Pesquisas Agrícolas e Florestais, 2015. 32p.

15. DIAS, J.E.; LAUREANO, L.C.; MING, L.C. Boas práticas de manejo para o extrativismo sustentável de gueroba. Brasília: Instituto Sociedade, População e Natureza, 2014. 168p.

16. CORRADO, A.R.; TOMCHINSKY, B.; BONFIM, F.G.; MING, L.C. Patrimônio cultural e biológico: desafios e perspectivas para conservação e uso. Botucatu: Fundação de Estudos e Pesquisas Agrícolas e Florestais, 2014. v. 1. 149p.

17. MING, L.C.; RIBEIRO, C.M.N.; FREGONESI, T.R.; RIBEIRO, M.A.S.; SANCHEZ, C.D.; SANTOS, B.R.; MOREIRA, M.S.; ERISMANN, C.; LOPES, N.; CABRAL, C.M.; VASCONCELLOS, M.C.; GARCIA, P.A.L. Manual Agroecológico. Botucatu: Edição do autor, 2013. 68p.

18. SOUZA, S.E.X.F.; MACEDO, G.S.S.R.; CHAGAS, G.F.; FREITAS, R.M.; OTTA, L.M.S.; SONCIM, I.Q.; OLIVEIRA, R.M.; SILVA, E.J.V.; MING, L.C. Além da merenda: aprendendo sobre juçara, cambuci e banana. Botucatu: edição dos autores, 2013. 24p.

19. MING, L.C. Ameixas secas. Botucatu: edição do autor, 2013. 110p. 
20. DUQUE-BRASIL, R.; SOLDATI, G.T.; SOUTO, F.J.B.; ALENCAR, N.L.; MING, L.C.; COELHO, F.M.G. Quando pensa que não... contos, causos e crônicas em Etnoecologia. Viçosa - MG: Edição dos organizadores, 2012. 340p.

21. MING, L.C. Lírios Amarelos. Botucatu: edição do autor, 2012. 100p.

22. MING, L.C.; AMOROZO, M.C.M.; KFFURI, C.W. Agrobiodiversidade no Brasil: experiências e caminhos da pesquisa. 2. ed. Recife: NUPEEA, 2012. 308p.

23. GAlVAO, A.C.; MORINO, B.C.; MING, L.C.; LIMA, L.P.E. ; OLIVEIRA, P.F.C. Ferramentas agroecológicas utilizadas na região de Iporanga, SP: o causo do seu Nestor. Botucatu: Fundação de Estudos e Pesquisas Agrícolas e Florestais, 2010. 40p.

24. SILVA, R.B.; MING, L.C. Polo de biotecnologia da Mata Atlântica: relatos de pesquisas e outras experiências no Vale do Ribeira. Jaboticabal: FUNEP, 2010. 347p.

25. MING, L.C. Grande Maçã. Botucatu: Fundação de Estudos e Pesquisas Agrícolas e Florestais, 2009. 294p.

26. MING, L.C. Zoneamento de ambientes na Reserva Extrativista Chico Mendes, Acre. Recife: NUPEEA - SBEE, 2007. 95p.

27. MING, L.C.; PEDROSA, E.C.; MACEDO, G.S.S.R.; MOTA, J.U.; STUCHI, J.F.; PROSPERO, R. Floresta do PETAR: árvores úteis na trilha do Betari. Botucatu: UNESP, 2006. 36p.

28. MING, L.C.; PEDROSA, E.C.; MOTA, J.U.; STUCHI, J.F.; MULLER, J.F.; PROSPERO, R. Iporanga: os saberes da floresta. Botucatu: UNESP, 2006. 88p.

29. CORREA JR, C.; SCHEFFER, M.C.; MING, L.C. Cultivo agroecológico de plantas medicinais, aromáticas e condimentares. Brasília - DF: Ministério do Desenvolvimento Agrário, 2006. 76p.

30. MING, L.C. Plantas medicinais na Reserva Extrativista Chico Mendes. São Paulo: Fundação Editora da Unesp, 2006. 160p.

31. MING, L.C.; CARVALHO, I.; VASCONCELlOS, M.C.; RADOMSKI, M.I.; COSTA., M.A.G. Direitos de recursos tradicionais: formas de proteção e repartição de benefícios.Botucatu: UNESP, 2005. 157p.

32. AMOROZO, M.C.M.; MING, L.C.; SILVA, S.M.P. Métodos de coleta e análises de dados em etnobiologia, etnoecologia e disciplinas correlatas. Rio Claro: UNESP, 2002. 204p.

33. AMOROZO, M.C.M.; MING, L.C.; SILVA, S.M.P. A etnobotânica e a conservação dos recursos genéticos. Rio Claro: UNESP, 2002. 212p.

34. MING, L.C.; BASTOS, S.; LOURENÇO, L.M. Horta de Itatinga: estórias e plantas medicinais na vida de seus moradores. Botucatu: Unesp, 2000. 65p.

35. MING, L.C.; GAUDÊNCIO, P.; SANTOS, V.P. Plantas medicinais: uso popular na Reserva Extrativista Chico Mendes. Nova York: Rain Forest Alilance, 1997. 125p.

36. ELISABETSKY, E.; TRAJBER, R.; MING, L.C. Manual de coleta de plantas medicinais em reservas extrativistas. São Paulo: edição dos autores, 1995. 36p.

Deve ser destacada a publicação de um livro ("Dentro dos seringais da Reserva Extrativista Chico Mendes") por um seringueiro, Paulo Gaudêncio, que colaborou fortemente nas atividades práticas desenvolvidas nas aulas e estágios de estudantes na Reserva Extrativista Chico Mendes, Acre, que contou com o patrocínio pessoal do Prof. Lin Chau Ming, em 2018 (Figura 10).

Foram também publicados diversos outros trabalhos acadêmicos na área, desde o início do oferecimento das disciplinas relativas ao conteúdo etnobotânico, com 40 artigos científicos em revistas, 28 capítulos de livros e ministrados 34 cursos e 23 palestras, em diferentes eventos e locais, além de centenas de resumos em congressos e outros eventos científicos.

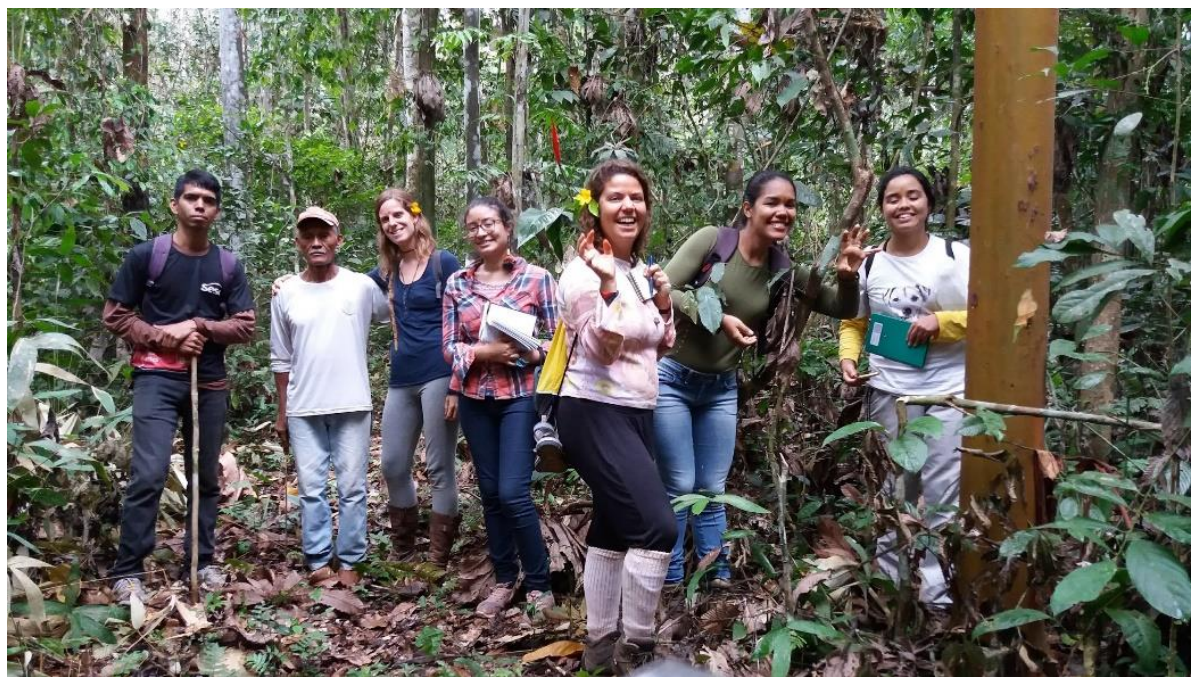


Figura 9. Aula prática e vivência na Reserva Extrativista Chico Mendes, Acre.

Desde sua implantação, as disciplinas de Etnobotânica têm atraído interesse de muitos estudantes e, com isso, também foram realizados 44 trabalhos de conclusão de curso de graduação e projetos de Iniciação Científica e defendidas 22 dissertações e 18 teses de, além de 4 pós-doutorados na FCA.

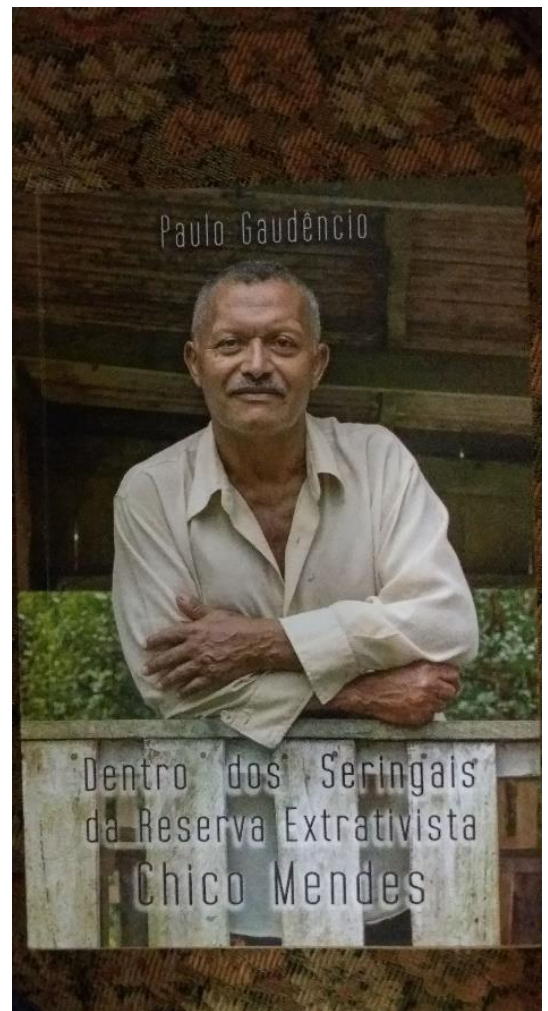

Figura 10. Livro escrito pelo seringueiro Paulo Gaudêncio.

\section{Desafios gerais e na FCA - UNESP - Botucatu}

Dentre alguns desafios colocados para a consolidação da área de Etnobotânica, há a necessidade de se oferecer disciplinas nas universidades e/ou faculdades que ainda não as oferecem. Para isso deve haver um maior intercâmbio entre os profissionais da área, discutindo formas para que isso possa ser mais rapidamente efetivado, bem como discutir conteúdos programáticos gerais. O intercâmbio interinstitucional poderia gerar também projetos em conjunto, o que seria altamente positivo.

Os trabalhos etnbotânicos deveriam também ser mais bem divulgados, com incentivo para que os professores e pesquisadores publiquem mais em periódicos relacionados à área. Houve também a discussão para a criação de uma revista científica específica, associada à Sociedade Brasileira de Etnobiologia e Etnoecologia, aumentando a possibilidade de veiculação dos trabalhos realizados, o que foi realizada em 2016, com o lançamento da revista Ethnoscientia.

A consolidação dos trabalhos na área ajudaria na maior visibilidade junto ao $\mathrm{CNPq}$ e outros órgãos de fomento, tanto em nível estaduais quanto nacional, e teria o reconhecimento dos pares acadêmicos.

Internamente, na FCA, estão em andamento algumas atividades para que a área seja melhorada. As exsicatas de trabalhos etnobotânicos já podem ser inseridas nos Herbários do Instituto de Biociências da UNESP-Botucatu e do Jardim Botânico do Instituto Agronômico de Campinas, em Campinas. Isso facilita sobremaneira os trabalhos e permite que os vouchers coletados sejam devidamente registrados. Mais recentemente, o Herbário do Instituto Federal de Educação de Manaus (HEAM) também autorizou a inserção de exsicatas de trabalhos etnobotânicos, com o crescente número de coletas realizadas por estudantes da FCA na região amazônica, em especial no Amazonas.

Já está também implantado um laboratório etnobotânico, incluindo local para preparo, secagem e armazenamento de material botânico, sala para alunos com infraestrutura adequada e uma biblioteca com livros e periódicos da área, possibilitando acesso mais facilitado a informações técnicas e científicas. 
Foi feita ainda a instalação de uma base física de apoio a trabalhos etnobotânicos no Vale do Ribeira, em Iporanga, SP, permitindo que os alunos de graduação e pós-graduação e outros pesquisadores tenham um local onde possam se instalar e melhor organizar as atividades de campo naquela região.

Também se pensou na implementação de proposta uma nova disciplina na área de Etnobotânica, complementar à já oferecida, com aprofundamento de questões teóricas e que também permitirá a realização de trabalho de campo com maior amplitude, além de serem buscadas novas parcerias acadêmicas para uma mais profícua relação de trabalho. Porém, esta proposta conta com dificuldades de ordem administrativo-burocrática da Universidade, além de exigir mais recursos para sua viabilização, pois se pensa em um período maior de vivência no campo, muitas vezes fora do Estado de São Paulo.

Com a aposentadoria do professor responsável da UNESP, a partir de julho de 2019, as disciplinas e atividades desenvolvidas poderão ser encampadas por professores que ainda permanecem na FCA, com apoio do professor aposentado, que segue ministrando disciplinas na área, em nível de graduação e pós-graduação, junto ao programa de pós-graduação em Agroecossistemas do Centro de Ciências Agrárias da Universidade Federal de Santa Catarina, em Florianópolis, para onde inseriu, como professor visitante sênior, desde agosto de 2019.

\section{REFERÊNCIAS}

ALVES, A.G.C. Ensino de Etnobiologia e Etnoecologia no Brasil: em busca de uma educação integradora. In: ENCONTRO BAIANO DE ETNOBIOLOGIA E ETNOECOLOGIA, 1, 2001, Feira de Santana. Anais... Feira de Santana: UEFS, 2001. p. 83-88.

AMOROZO, M.C.M.; MING, L.C.; SILVA, S.M.P. (Eds.) Métodos de coleta e análise de dados em

Etnobiologia, Etnoecologia e disiciplinas correlatas. Botucatu: UNESP/CNPq, 2002. p. 181-204.

COSTA NETO, E.M. Cinco anos de Etnobiologia na UEFS. In: ENCONTRO BAIANO DE

ETNOBIOLOGIA E ETNOECOLOGIA, 1, 2001, Feira de Santana. Anais... Feira de Santana: UEFS, 2001. p. 75-81.

FONSECA-KRUEL, V.S.; SILVA, I.M.; PINHEIRO, C.U.P. O ensino acadêmico da Etnobotânica no Brasil,

Rodriguésia, v. 56, n. 87, p. 97-1006, 2005.

INSTITUTO SOCIOAMBIENTAL (ISA). Povos indígenas no Brasil 2010-2016. São Paulo: ISA, 2016.

MARQUES, J.G.W. O olhar (des)multiplicado. O papel do interdisciplinar e do qualitativo na pesquisa etnobiológica e etnoecológica. In: AMOROZO, M.C.M.; MING, L.C.; SILVA, S.M.P. (Eds.). Métodos de coleta e análise de dados em Etnobiologia, Etnoecologia e disciplinas correlatas. Botucatu: UNESP/CNPq, 2002. p. 31-46.

MING, L.C. Elaine Elisabetsky, etnofarmacóloga pioneira no Brasil. Ethnoscientia, v. 3, n. 2(especial), 2018. D.O.I.: 10.22276/ethnoscientia.v3i2.180

SERRA, O. Como plantar etnobiólogos: um cruzamento difícil na Bahia. In: ENCONTRO BAIANO DE ETNOBIOLOGIA E ETNOECOLOGIA, 1, 2001, Feira de Santana. Anais... Feira de Santana: UEFS, 2001. p. 71-73. 